\title{
DO DESENVOLVIMENTO À MATURIDADE DA REDUÇÃO FENOMENOLÓGICA (1905-1913)
}

\author{
From Development to Maturity of the Phenomenological Reduction (1905-1913)
}

Del Desarollo a la Madurez de la Reducción Fenomenlógica (1905-1913)

Resumo: Com o escopo de reconstituição histórico-epistemológica, expõe-se uma análise temporal do conceito "Redução Fenomenológica" em seus aspectos principais em obras de Husserl datadas de 1905 a 1913. Encontraram-se duas fases do conceito (1905-9/ 1910-13). A primeira diz respeito ao seu começo, enquanto início de uma Teoria do Conhecimento. Já a segunda versa sobre aquisições que obras posteriores mais maduras evocaram. Conclui-se o trabalho com reflexão de que a Redução Fenomenológica tem um indiscutível caráter de constância no pensamento de E. Husserl.

Palavras-chave: Fenomenologia; Epistemologia; Redução Fenomenológica; História da Filosofia.

\begin{abstract}
With the goal of historical-epistemological reconstitution, a temporal analysis of the concept of "Phenomenological Reduction" is presented in its main aspects in works by Husserl dating from 1905 to 1913 . Two phases of the concept were found (1905-9 / 1910-13). The first one is about its beginning with its place as a starting point of a Theory of Knowledge. The second one is about acquisitions that later works have evoked. The paper ends up with the conclusion that with the reflection that the Phenomenological Reduction has an indisputable character of constancy in the thought of E. Husserl.
\end{abstract}

Keywords: Phenomenology; Epistemology; Phenomenological Reduction; History of Philosophy.

Resumen: Con el objetivo de la reconstitución histórico-epistemológica, se presenta un análisis temporal del concepto de "Reducción Fenomenológica" en sus aspectos principales en obras de Husserl que datan de 1905 a 1913. Se encontraron dos fases del concepto (1905-9 / 1910-13). El primero es su comienzo con su lugar como inicio de una Teoría del Conocimiento. El segundo se trata de adquisiciones que las obras maduras posteriores han evocado. El documento termina con la conclusión de que con la reflexión de que la Reducción Fenomenológica tiene un carácter indiscutible de constancia en el pensamiento de E. Husserl.

Palabras clave: Fenomenología; Epistemología; Reducción Fenomenológica; Historia de la Filosofía.

\section{Introdução}

A Redução Fenomenológica é, em seu aspecto metodológico, um dos (senão o) conceitos mais importantes para se entender a filosofia transcendental husserliana. Assim, é já justificado qualquer esforço no sentido da fundamentação epistemológica de tal noção.

É exatamente nesse sentido que esta pesquisa caminhou. Propomos aqui uma reconstituição histórica de tal conceito na obra de Edmund Husserl. Pelo termo sublinhado, entende-se duas atitudes básicas. Em primeiro lugar, buscou-se expor o constructo analisado em suas principais consequências teórico-epistemológicas, junto com os conceitos aí diretamente relacionados. Também, tentou-se apontar suas mudanças e continuidades neste período de tempo, informando, ao final, o grau de persistência que a formulação guarda.

Em igual medida, à guisa de encontrar um recorte temático compatível com a extensão de um arti- go, pretendeu-se empreender tal reconstituição para a Redução Fenomenológica em um período temporal decisivo para o afloramento das noções fundamentais da Fenomenologia, que acompanharam o percurso do pensamento do autor. Tal momento inicia em 1905, com a postulação oficial do conceito. Nesse período, Husserl estava em um claro momento de transição de sua antiga Psicologia Descritiva, das Investigações, para o horizonte de transcendentalidade característico da Fenomenologia. Nosso período de análise finaliza em 1913, ano de publicação do talvez livro mais emblemático da fenomenologia husserliana e marco de uma maturação importante do pensamento do filósofo.

\section{1905-1909 \\ O início do conceito}

O emprego da Redução Fenomenológica (Phänomenologische Reduktion) (ou seus análogos embrio- 
nários) parece ser coextensivo com o próprio advento da Fenomenologia. Desde o começo de suas pesquisas, quando finalmente se deu conta deste "novo" horizonte de investigações aberto, o autor percebeu a necessidade, aí implícita, de um artifício metodológico que corretamente pudesse delinear e delimitar os objetos de interesse desta ciência, ou seja, seu domínio. Em socorro deste imperativo, já nos escritos (pré)fenomenológicos o filósofo postula, na quinta das Investigações Lógicas (Husserl, 1901/2015), algo neste sentido, a saber, o "Princípio da Ausência de Pressupostos" (Das Princip der Voraussetzungslozigkeit). Este preceito tem a função básica de isolar, para a pesquisa, o que é "puramente descritivo" de vivências, ou seja, o que está contido no seu acervo fenomenológico (Reell) e não o ultrapassa ${ }^{1}$.

Exemplo de eventos semelhantes ocorrem, posteriormente, em escritos sobre a consciência interna do tempo. Precisamente, dento dos documentos chamados "A suspensão do tempo objetivo, o objeto temporal, a fenomenologia da objetificação e sua aporia”, o de manuscrito de número $19^{2}$, que data de 1904, é de especial importância. Neste texto, Husserl (1966/1980) indica que, para que haja uma análise fenomenológica (imanentemente interpretada) da experiência sobre o tempo e sobre o espaço, tem que haver uma completa exclusão (ou abstração) das suposições ("transcendentes") a respeito do tempo e espaços objetivos, juntamente a qualquer referência às gêneses psicológicas (qua origem metafísica) naquelas noções. Com isto, se saca os campos visuais e espaciais originários, livres de transcendências das noções objetivas. Assim, se exclui tudo aquilo que não pode ser encontrados nas vivências, "enquanto imanências autênticas” (Husserl, 1966/1980, p.40).

Contudo, os dados documentais mostram que o conceito de "Redução Fenomenológica" só foi postulado, explicitamente, na assim chamada "Reflexão de Seefeld", que é constante no esboço de número 35 (datado das férias de verão de 1905) dos, assim chamados, "Manuscritos de Seefeld sobre Individuação" (Seefelder Manuskripte über Individuation). Numa nota posterior sobre este trabalho, o próprio filósofo aponta que "já acho o conceito e o uso correto da 'redução fenomenológica' nas folhas de Seefeld de 1905” (Husserl, 1966/1980, p. 145, tradução nossa). O conceito é assim postulado:

Eu percebo este marrom, eu empreendo uma Redução Fenomenológica, portanto tomo o

\footnotetext{
1 Como a pesquisa aqui empreendida tem como abrangência apenas a formulação explítica do conceito, optamos por fazer apenas esta breve exposição. Para posições mais aprofundadas sobre a vinculação das Investigações à Redução Fenomenológica (ver, e.g., Lohmar (2003) e Lavigne (2003)).

2 O teor desta exposição está presente, também, na Introdução às "Conferências à Consciência Interna do Tempo" (1905). Sobre aquele intento eliminatório, a fim de estabelecer seu solo investigativo, o autor chega a afirmar que "tal como a coisa real, o mundo real não é um dado fenomenológico, como também não o é o tempo do mundo, o tempo real, o tempo da natureza no sentido das ciências naturais e também da psicologia, como ciência natural do psíquico" (Husserl, 1966/1994, p.38).
}

puro dado de sensação tal como é dado fenomenologicamente, como agora durando. Isto este marrom - dura: ele permanece sem mudar; tem sempre a mesma extensão ao longo de sua duração. Ele muda: ele - este marrom - muda em qualidade, em brilho (torna-se mais escuro); sua extensão [muda - a extensão que ele preenche, que ele cobre (Husserl, 1966/1980, p. 261, tradução nossa, grifo nosso).

O conceito nasce, como o nome já sugere, muito atrelado à noção de "fenômeno" (em sua imanência). Não ir além do que é intrínseco à imanência vivencial é a preocupação primeira para este Husserl. A redução, portanto, deveria excluir aquilo que não pertencesse a isso. "Eu excluo o que é meramente significado e não dado no fenômeno" (Husserl, 1966/1980, p. 246, grifo nosso).

\section{A maturidade do conceito e "crítica do conhecimento"}

A Redução Fenomenológica, contudo, só ganhou seus contornos mais maduros depois, em 1906 e 1907, nas conferências que, por exemplo, deram origem às obras "A Ideia da Fenomenologia" (Die Idee der Phänomenologie) e "Introdução à Lógica e a Teoria do Conhecimento" (Einleitung In Die Logik Und Erkenntnistheorie). A identidade conceitual da Redução Fenomenológica ganha seus contornos mais definitivos, propriamente, por vir diretamente em socorro da Crítica do Conhecimento (Erkenntniskritik) empreendida por Husserl ${ }^{3}$.

Sobre este aspecto, é importante salientar que Husserl (1954/2008b; 1984/ 2008c) parte de uma tomada de posição totalmente distinta das ciências naturais, que são eminentemente dogmáticas. Para ele, a filosofia deve se preocupar com os problemas da possibilidade do conhecimento. A filosofia é, portanto, por excelência, crítica do conhecimento. Pôr o conhecimento em questão não significa para Husserl, todavia, negar toda e qualquer possibilidade deste. Diferentemente disto, devemos, de partida, reconhecer que o conhecimento reserva em si um certo problema, uma obscuridade, não em sua totalidade, mas em alguns aspectos.

Desse modo, empreendemos uma crítica de dentro do próprio conhecimento, a fim de encontrar aí claridade, indubitabilidade. A crítica não pode se mover senão pelo guia absoluto da "clara et distincta perceptio". Em outras palavras, Fenomenologia do Conhecimento tem como objetivo "elucidar a essência do conhecimento e da objetalidade cognitiva" (Husserl, 1984/2008b, p. 44).

\footnotetext{
3 Sobre a vinculação entre fenomenologia e teoria do conhecimento, o autor afirma que "Nenhuma teoria do conhecimento sem fenomenologia. Mas fenomenologia também retém significado independente da teoria do conhecimento, independentemente do interesse de esclarecer esses notáveis erros e confusões nos quais reflexão sobre conhecimento natural torna-se emaranhado. " (Husserl, 1984/2008c, p.213, grifo do autor, tradução nossa)
} 


\section{A importância da imanência reelle 4 como "ponto de partida" para a teoria do conhecimento}

Assim sendo, para empreendermos uma crítica do conhecimento devemos, seguindo Husserl, ter um ponto de partida totalmente claro e livre de qualquer possibilidade de dúvidas. Elege-se a cogitatio cartesiana como estes "primeiros dados absolutos" (Husserl, 1954/2008b, p. 21). Para tanto, justifica-se, inicialmente, a inquestionabilidade das cogitationes e a questionabilidade dos conhecimentos das Ciências Naturais pelo par imanência/transcendência ${ }^{5}$.

No caso da "atitude natural", temos seu caráter enigmático e obscuro, pois trata-se aqui da composição de um conhecimento eminentemente transcendente. Neste aspecto, temos um dado que intenta ir "para além” de si mesmo, sendo, por isto, não imanente. Em outras palavras, "põe ${ }^{6}$ objetos como existentes, pretende atingir cognoscitivamente estados de coisas que não estão nele 'dados no verdadeiro sentido', não lhe são imanentes” (Husserl, 1954/2008b, p. 58). A crítica do conhecimento, portanto, não pode, numa atitude dogmática, lançar mão, sem mais deste tipo de dado, assim como faz as ciências naturais ao tomar, sem mais, a tese de um mundo empírico, pretensamente de indiscutível existência. Ela só pode, seguindo aquela exigência, partir de um conhecimento inteiramente evidente.

O conhecimento transcendente, mediante o crivo da crítica do conhecimento, só ocupa, em tal sentido, este lugar de destaque unicamente porque sua transcendência apresenta, de uma maneira preliminar, o caráter de enigmática, problemática. Isso ocorre porque esta "ida” para além da imanência, o que pode parecer um “a mais”, é, na verdade um "passo em falso" dogmático e inseguro dado pelo cientista natural. Para Husserl, a questão é que não podemos ter certeza, inicialmente, de algo que se intenta ir para fora do próprio ato de conhecimento. "Como pode o conhecimento estar certo de sua consonância com os objetos conhecidos, como pode ir além de si e atingir fidedignamente os objetos?” (Husserl, 1954/2008b, p. 40, grifo nosso). Desse modo, a transcendência aparece para a Fenomenologia como "problema inicial e guia da crítica do conhecimento; é o enigma que bloqueia o caminho do conhecimento natural e constitui o impulso para as novas investigações" (Husserl, 1954/2008b, p. 59). Logo, a teoria do conhecimento, que tem pretensão de clareza indiscutível, não poderia, de partida, lançar mão desse tipo de dado.

Como se pode ter notado, Husserl apenas define o conceito de transcendência, nestas obras, por via negativa, sempre se remetendo a uma "não-imanên-

\footnotetext{
4 Neste momento da obra, de maneira intercambiável, de termos da tradição cartesiana, como "cogito", "cogitatio" ou "cogitationes" para indicar conteúdos desta ordem, ou seja, aqueles que estão inteiramente contidos nas vivências.

5 Atente que estamos, até ser indicado o contrário, nos referindo ao chamado primeiro sentido deste par conceitual (a ser distinto do segundo, mais a frente, em momento oportuno).

6 Fala-se aqui de atos téticos, ou seja, de crença.
}

cia”. Obviamente, é necessária aqui uma maior explanação sobre o conceito de imanência, retomando sua relação com a "evidência primeira”, as cogitationes. O conceito que contrasta, de início, ao conceito de transcendência é o de imanência inclusa ${ }^{7}$. Aqui não há aquele "para além” do dado transcendente. Em outras palavras, na imanência inclusa ficamos dentro da vivência, não intentamos, de maneira alguma, atingir algo que não está realmente contido aí.

É possível afirmar, deste modo, que a cogitatio está livre do "enigma” que perpassa as transcendências. O imanente incluso é, portanto, um dado absoluto e indubitável. Como este conhecimento nada intenta "para além de si mesmo", o que está dado aí é, ao mesmo tempo autodado, de maneira perfeitamente adequada. Em outras palavras,

(...) graças a esta imanência, está livre da qualidade de enigmático, que é a fonte de todas as perplexidades cépticas; e ainda, finalmente, que a imanência em geral é o caráter necessário de todo o conhecimento teórico-cognoscitivo e que, não só no começo, mas em geral, todo o empréstimo a partir da esfera da transcendência - por outras palavras, toda fundamentação da teoria do conhecimento na psicologia ou qualquer ciência natural, é um non-sens (Husserl, 1954/2008b, p. 57).

É por causa desse caráter evidente e absoluto que nos é autorizado utilizar o ser das cogitationes ${ }^{8}$ em nossa Teoria do Conhecimento. O contrário se aplica, portanto, ao dado transcendente: não podemos de este lançar mão. Faz-se necessário, então, uma espécie de redução que opere uma exclusão, uma purificação. Trata-se, com efeito, de uma redução ao fenômeno qua conteúdo reell de vivências. Não podemos aceitar, de início, portanto, nada além do "fenômeno puro"9, contido no ato de conhecer em sua imanência inclusa, mediante uma "visão pura” (Husserl, 1954/2008b, p .57).

Dessa maneira, a Redução Fenomenológica nos diz: "a todo transcendente (que não me é dado imanentemente) deve atribuir-se o índice zero, isto é, a sua existência, a sua validade não devem pôr-se como tais" (Husserl, 1954/2008b, p. 23). O que se requer do fenomenólogo é, portanto, que abra mão de atos de crença ${ }^{10}$ em relação ao transcendente. Não

\footnotetext{
7 Termo utilizado por Arthur Mourão (tradutor da obra "Ideia da Fenomenologia" para o português) para designar "reelle".

8 É por esta vinculação a este dado, pretensamente capaz de despistar os desafios céticos, enquanto início metodológico, que estamos autorizados a identificar esta modalidade de Redução como representante da "via cartesiana" (dentre aquelas três elencadas por Kern (1962)).

9 Em oposição ao "fenômeno psicológico" da atitude natural.

10 Nesta época, ainda persiste a distinção "mera representações" (termo permanece idêntico ao uso das Investigações), por um lado, e "juízos existenciais" (o que, curiosamente para Husserl, não indicavam apenas aos atos que colocavam existência real [real], mas generalizava para toda classe de atos posicionais), por outro, para marcar a diferença entre os que põem validade e aqueles em que isso não ocorre. $\mathrm{O}$ autor também ainda entendia que poderia haver uma modificação de uma para a outra, de modo a não se colocar mais algo como “existente", de maneira "posicional" (Husserl, 1987/2008a).
} 
podemos aí pôr nenhuma validade, não podemos, a respeito dele, julgar nada em relação ao ser ou não ser. Em outras palavras,

(...) em toda inquirição teórico-cognoscitiva, quer se trata deste ou daquele tipo de conhecimento, há que levar a cabo a redução gnosiológica, isto é, há que afectar toda a transcendência concomitante com o índice da desconexão, ou com o índice da indiferença, da nulidade gnosiológica, com um índice que afirma: não me importa aqui absolutamente nada a existência de todas estas transcendências, que eu nelas creia ou não; aqui, não é o lugar de sobre ela julgar; isso fica completamente fora de jogo (Husserl, 1954/2008b, p. 63).

Não se trata, contudo, aqui de uma "exclusão" no sentido radical do termo, ao molde de um total "desaparecimento" ou de uma negação da existência. Na verdade, trata-se, antes, de um duplo movimento. Temos, por um lado, a renúncia ao ato de crença em relação a isso e, por outro, a mudança do "modo de apreensão" deste dado. Se outrora se tratava de uma transcendência, agora aquele mesmo dado deve ser tomado de maneira imanente, como "mero fenômeno". Destarte, todas as Ciências Naturais - notadamente por seu caráter transcendente - são, para a Fenomenologia, simples "fenômenos de ciências", não sistemas de validade. Não falamos aqui de pessoas ou fatos no sentido natural, mas sim de "pessoas-fenômeno" ou "fato-fenômeno". É assim que Husserl (1954/2008b) requer renúncia aos pressupostos transcendentes de todo e qualquer trabalho intelectual das Ciências Naturais. Em suma, conforme Bernet, Kern e Marbach (1999, p.61, tradução nossa) "a realização apropriada da Redução Fenomenológica [é] por meio de uma desvinculação consistente da apercepção empírico-natural de consciência”.

Levando em consideração tudo isto que foi reconstruído, a título de conclusão da seção, pode-se dizer que Redução, neste sentido, é um método motivado. Isto quer dizer que ela se dá em direção a um sentido ou uma finalidade específica, que é conforme mostrado, de natureza marcadamente epistemológica. Deste modo, tal como Descartes, Husserl deseja, com este procedimento, "sair" da obscuridade cognoscitiva para um horizonte de clara et distincta perceptio da evidência. Isto diz respeito à distinção feita por Braidnard (2003) entre caminhos para se desempenhar a epoché (neste caso, o objetivo de um começo absoluto, anterior ao próprio método) e a epoché (enquanto implementação (metodológica) efetiva).

\section{Fenomenologia para além da cogitatio}

Diante do que expomos até aqui, pode-se pen-

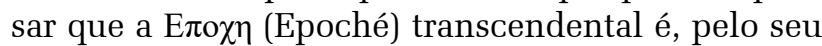
caráter exclusivo, na verdade, uma limitação radical a nada além do imanente incluso. Isto, contudo, seria uma opinião falsa. Como bem nos adverte o filósofo, o campo de tarefas da Fenomenologia "não é coisa tão trivial como se apenas houvesse que olhar; simplesmente abrir os olhos" (Husserl, 1954/2008b, p. 31), como a redução ao fenômeno puro pode sugerir. Pode-se (e deve-se) trabalhar com outros tipos específicos de dados.

Husserl (1954/2008b) nos oferece, na verdade, duas maneiras de entender o par imanência/transcendência. Como nosso objetivo até então foi apreender a evidência donde parte a Redução Fenomenológica, abordamos apenas a primeira definição, a saber, a oposição entre imanência inclusa e o que não está aí ingrediente. $\mathrm{O}$ autor, contudo, oferece-nos, em segunda instância, uma forma bem mais ampla de abordar essa dupla, em maior confluência com a vocação epistemológica defendida.

Em segunda definição, imanência pode ser entendida como aquilo que "está dado, que exclui toda a dúvida sensata", o que constitui o "conceito pleno de evidência e claro, entendida como evidência imediata” (Husserl, 1954/ 2008b, p. 59). Transcendência seria tudo aquilo que não apresenta este caráter, que não é evidente; que põe o objetal, mas não o intui ele mesmo, de modo que "vamos além do dado em cada caso no verdadeiro sentido, além do que diretamente se pode ver e captar" (Husserl, 1954/ 2008b, p. 59).

Isto ocorre porque o campo da Fenomenologia é aquele do autodado, daquilo que é dado tal qual é visado, ou seja, em que as coisas mesmas se nos apresentam.

A redução fenomenológica não significa a limitação da pesquisa à esfera da imanência ingrediente [reelle], à esfera do incluído como ingrediente [reelle] no isto absoluto da cogitatio; não significa de modo algum o confinamento à esfera da cogitatio, mas a restrição à esfera do dar-se em si puro, à esfera daquilo de que não só se fala e que não só se intenta; também não à esfera daquilo se percepciona, mas à esfera do que está dado exatamente no sentido em que é visado e autodado (Husserl, 1954/ 2008b, p. 88).

É por isso que o autor defende a intuição como via para o conhecimento absoluto, pois

(...) apenas intuições são presentações ${ }^{11}$ autênticas. Intenções vazias estão direcionadas para objetos, mas não são "autenticamente" presentações deles. Eles não fazem um objeto "ficar diante de nós", apenas aparece. Presentações autênticas captam o objeto ou o retratam (Husserl, 1984/2008c, p. 275, tradução nossa).

11 Husserl usa o termo "Gegenwärtigung" para se referir "aquelas vivências nas quais os objetos intencionais são dados na experiência intuitiva, imediatamente, diretamente, e com in propria persona, 'na carne' (leibhaftig), aqui-e-agora, ampla presença, e.g. a maneira que o objeto é presentado nos atos de percepção" (Moran \& Cohen, 2013, p.260, grifos dos autores, tradução nossa). 


\section{A ampliação intencional}

Ainda na esfera da Redução Fenomenológica, portanto, existe outro tipo de dado além do reelle de

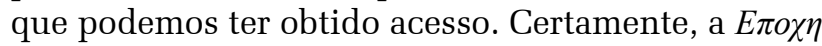
filosófica nos permite estar no âmbito do imanente incluso. Por mais paradoxal que possa parecer, contudo, segundo o filósofo, as cogitationes, mesmo reduzidas, ainda, "ocultam transcendências de toda índole" (Husserl, 1954/2008b, p. 29, grifo nosso).

É pela via da intencionalidade que a esfera de investigações é aqui primeiramente ampliada. Esta característica dos atos cognitivos ("de conhecimento") que justamente irá levar-nos mais adiante do dado imanente reelle. Uma vivência pura (portanto, já reduzida) exige a oposição entre o fenômeno e aquilo que aparece, enquanto seu objeto; esta é uma "correlação essencial”. Desse modo, "é próprio delas [das vivências cognitivas] referir-se a uma objetalidade" (Husserl, 1954/2008b, p. 81). Por mais que uma vivência possa se referir a um objetal $(G e-$ genständlich), ele não pode estar aí contido. Ele a extrapola. Na verdade, as coisas se constituem ${ }^{12}$ nas vivências ${ }^{13}$. Elas são visadas, exibindo-se. É daí que Husserl justifica o direito de falar do objetal como o "imanente no sentido intencional", diferenciando-o do imanente reelle. A investigação deve, assim, verificar ambos desses lados.

É por esse meio que a Fenomenologia torna-se capaz de investigar o tempo, por exemplo. Na realidade, estamos num fluxo temporal, um verdadeiro "rio heraclidiano de fenómenos" de vivências que passam, mas o objetal, por essência, dura. ${ }^{14}$

\section{A correta delimitação da Redução Fenomenológica}

Ao leitor, neste momento, pode restar um momento de confusão. Em primeiro lugar, apresentamos a Redução Fenomenológica como uma exclusão de tudo aquilo que não está contido na cogitatio, as

12 Husserl usa o termo "Konstituition" para designar a noção de que objetos são constituídos em doação de sentido de uma subjetividade.

13 Daí Husserl afirmar que, por outro lado, as objetalidades, apesar de serem individualmente separadas do fenômeno, são dele essencialmente inseparáveis. Elas só podem ser dadas no e em virtude do fenômeno.

14 Neste ponto, somos obrigados a discordar de Tourinho (2012, p.32) (que parece seguir a opinião de Kern (1962)) quando este afirma que "Husserl - impulsionado pelo projeto de fundamentação da filosofia como ciência rigorosa - vai além da evidência da cogitatio e, nesse sentido, pode-se dizer que ele vai além de Descartes, ao generalizar a suspensão de juízo, afirmando-nos que mesmo a nossa vivência psicológica deverá cair sob o golpe da epoché fenomenológica, pois tal vivência é a vivência de um "sujeito empírico" - de um ente psicofísico, objeto de estudo da ciência psicológica - e, portanto, encontra-se inserido em meio a outros entes mundanos, submetido, da mesma forma, a uma dimensão espaçotemporal". Como veremos a seguir, é verdade que Husserl não pode se contentar com meros dados do tipo "cogito" para suas pretensões filosóficas. Mas isto não ocorre porque temos aí "vivências psicológicas", segundo os moldes, e.g., da "Psicologia Fenomenológica" posterior (Husserl, 1962/2001) ou da redução ao que é "fenomenologicamente realizável" do princípio da ausência de pressupostos (que, na interpretação posterior de Husserl remete a um eu empírico) (Husserl, 1901/2015). Como estamos vendo, este dado é alheio a qualquer carga transcendente (no sentido "incluso"), de que a hipótese de mundo externo (a que a psicologia se atém) é inteiramente tributária. Assim, as cogitationes não podem ser, por seu caráter de meros dados subjetivos fugidios (momentâneos) e atuais, vinculadas, de todo, ao mundo real. transcendências. Depois, dissemos que, na verdade, a Redução é uma restrição ao dado evidente da intuição. A partir disso, dissemos que a Redução não pode pôr para fora de circuito as objetalidades que, por excelência, não são, de forma alguma, dados imanentes, no sentido primeiro apresentado (reell), o que as tornaria, na verdade, "transcendentes". Expliquemos essa aparente "contradição".

De fato, a Redução Fenomenológica é uma exclusão de tudo aquilo que não é fenômeno puro. Contudo, como vimos, não podemos pensar uma vivência senão correlatada com sua objetividade. Logo, a Redução Fenomenológica, entendida nesta época, é, por excelência, um método que nos leva a esses dois elementos.

As dificuldades aqui, contudo, parecem só aumentar. Pergunta-se: "conhecimentos intuitivos podem ou não ser encontrados na singularidade do fenômeno reduzido?". Como sabemos, Husserl não considera essências como imanentes inclusos, mas, mesmo assim, só podemos obtê-las por via intuitiva. Vamos à questão principal: "a Redução Fenomenológica admite ou não conhecimentos intuitivos que sejam transcendentes no primeiro sentido (reell) e que não sejam objetalidades?" Segundo nossa análise, podemos responder tanto afirmativamente quanto negativamente a esta pergunta. Ora Husserl (1954/2008b) fala de uma "Epoché em relação a toda transcendência ${ }^{15}$ " (p. 45, grifo nosso); ora afirma que a "restrição a esfera do dar-se em si puro" (p. 88), parecendo pôr fora de circuito apenas o segundo conceito de transcendência (o não autodado).

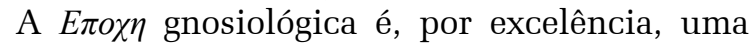
redução à cogitatio e, por essência, a sua objetalidade. A outros conhecimentos intuitivos, como as essências - nossa análise sugere - deve-se permitir no sentido de possibilidades um momento "ulterior"16 17 às cogitationes reduzidas, um "não se fechar às intuições posteriores" dado seu caráter epistemológico. Além disso, tais conhecimentos devem sempre ter como base os dados absolutos do fenômeno reduzido.

Citemos a questão da intuição de essência. A Redução Fenomenológica é um primeiro passo necessário ao conhecimento eidético, àquilo que, nesta fase, Husserl chama abstração ideativa (ideierende Abstraktion). O fenômeno puro é aquilo a partir do qual se funda o conhecimento propriamente de essência, o "verdadeiramente transcendente". Ele tem, sobretudo, um caráter exemplar do que é dado

\footnotetext{
15 Com essa citação, podemos entender que isto inclui elementos transcendentes segundo o primeiro sentido de "transcendência", como, por exemplo, o "transcendente em sentido verdadeiro", o universal.

16 Esta conclusão não é dada diretamente por Husserl. Ela foi inferida por nossa pesquisa pelas inúmeras vezes que Husserl indica o caráter "singular", em oposição ao universal (que seria obtido como um "segundo passo"), da redução fenomenológica.

17 Husserl, ao falar de conhecimentos intuitivos outros além da cogitatio (principalmente, como veremos a seguir, em relação à intuição de generalidades) refere-se como estes fossem, digamos assim, um "passo posterior" ao dado singular da cogitatio, dando sempre a ideia de uma "linearidade em sucessão".
} 
geral. Em outras palavras, conexões de essência tiram seu "subsolo" das cogitationes; se dão "sobre o fundamento dos fenômenos singulares da redução fenomenológica” (Husserl, 1954/2008b, p. 84). A Redução Fenomenológica é, portanto, uma exclusão do dado transcendente no sentido natural (o transcendente em geral, como existência a admitir), mas nunca poderia ser uma restrição radical ao dado imanente reell. Deve-se permitir, posteriormente, um uso, notadamente transcendente (segundo aquele primeiro sentido), de que, desses "primeiros dados", pode-se tirar.

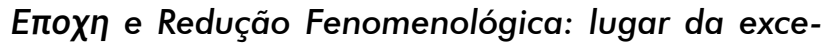 ção na teoria do conhecimento}

Concluímos a presente seção com uma breve reflexão sobre o caráter epistemológico que a Redução Fenomenológica ocupa nesta fase do pensamento husserliano. A título de ilustração da importância de tal característica, nesta época, Husserl utilizou o termo "Redução Gnosiológica" (erkenntnistheoretisch Reduction) como sinônimo de "Redução Fenomenológica". Como vimos, nestes anos "teoria do conhecimento" e fenomenologia eram, frequentemente, usados, em grande medida, quase de maneira intercambiável. É daí, que a Redução Fenomenológica só faz sentido, seguindo a lógica de Husserl, se for aceito, como objetivo primeiro, anterior, a ob-

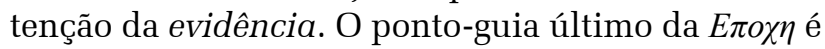
este. Como já citamos, o que se quer com a crítica do conhecimento é, única e exclusivamente, a clara et distincta perceptio.

É daí que tiramos o que Husserl chama de "ponto de partida" para crítica do conhecimento, a cogitatio. Só nos é lícito utilizar o conhecimento imanente incluso porque este é absoluto, indubitável. É esta, no momento da obra que tratamos, a única justificativa para a utilização de tal dado. Assim, a Redução Fenomenológica só pode operar depois do reconhecimento dessa tal "esfera de dados absolutos" aberta

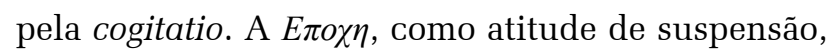
é uma pura "negatividade do conhecimento"18. Ela nunca poderia ser utilizada indiscriminadamente numa teoria do conhecimento, pois ela acabaria por não pôr nenhum conhecimento como válido, se limitando a tudo suspender. Seguindo o autor,

(...) se nós adotarmos a tomada de posição da epoché absoluta requerida, e nós fizermos uso de nenhum conhecimento estabelecido, se nós colocarmos toda e qualquer coisa em suspenso, então nós obviamente não falhamos em fazer nada, mas também não retemos coisa alguma. Nós não temos nenhum pedaço de conhecimento. (Husserl, 1984/2008c, p. 189, tradução nossa)

18 Ou neutralidade, como se queira.
Desta maneira, a Redução Fenomenológica trabalha segundo uma lógica de exceção. Ela importa para crítica do conhecimento (e sua busca pela claridade) justamente pelo que ela não atinge. Em outras palavras, a $E \pi \circ \chi \eta$ é, por excelência, uma operação de purificação. Ela deve desembaraçar o conhecimento da transcendência, pois esta é enigmática, e ceder lugar somente para aquilo que é evidente. O autor ilustra essa lógica da exceção afirmando que

(...) não nos é lícito aceitar ser algum como previamente dado, porque a obscuridade crítico-gnosiológica faz com que compreendamos que sentido pode ter um ser seja em si; e que, no entanto, seja conhecido no conhecimento, então deve poder mostrar-se um ser que devemos reconhecer como absolutamente dado e indubitável, na medida em que está dado justamente de um modo tal que nele existe plena claridade, a partir do qual toda pergunta encontre e deva encontrar sua resposta imediata. (Husserl, 1954/2008b, p. 52, grifo nosso)

Aqui cabe notar, ainda, neste contexto, o caráter de referência necessária entre a atitude natural e a Redução nestes aspectos mais marcadamente metodológico. Merleau-Ponty (1960), e.g., é um autor que nota a insistência husserliana em destacar o começo da reflexão fenomenológica na atitude natural enquanto crença primordial (Urdoxa). No mesmo sentido vai Júlio Fragata (1963, p. 198) quando afirma que "a partir da mesma fenomenologia de Husserl, se evidencia a exigência de uma 'atitude natural', embora intimamente reflexa, como início fundamental de todo o saber". Sobre isto, defendemos ser este aspecto compatível com o caráter de "negatividade" que atribuímos à Redução Fenomenológica, pois são justamente as crenças constantes nesta atitude que são aqueles alvos primeiros da suspensão. Colocando este caráter metodológico de outra forma, a Redução, como começo, só pode operar, segundo a maneira descrita, quando há algo a partir do qual começar enquanto "insumo", ou seja, as crenças naturais.

Além disto, esta discussão, de uma maneira ge-

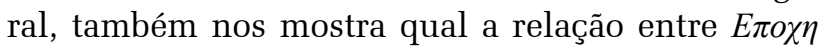
e Redução Fenomenológica. Ao contrário do que é comumente afirmado e ainda que, em uma primeira leitura, pela terminologia husserliana, este seja um uso aparentemente lícito, não devemos utilizar tais termos como sinônimos absolutos. Na verdade, é possível afirmar que a Redução Gnosiológica pra-

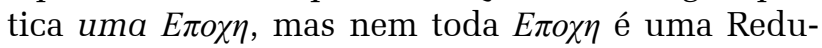
ção Gnosiológica. Isto acontece porque, como vimos

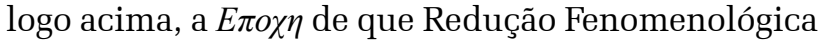
lança mão só é possível, pela posição que ela ocupa em sua crítica do conhecimento, em relação a um tipo de conhecimento específico, a saber o transcendente da atitude natural. Se não houvesse essa res- 
trição, não poderia existir teoria do conhecimento de

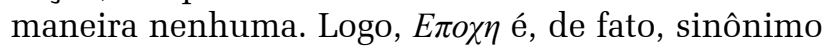
de "colocar fora de circuito", "suspender", "colocar entre parênteses”. Contudo, ela só é usada pela Fenomenologia na medida em que haja uma exceção ao que ela pode atingir. Devemos entendê-la como sinônimo de Redução Fenomenológica quando Husserl

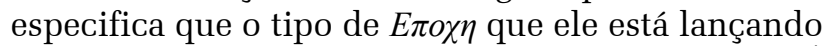
mão é aquele com interesses fenomenológicos. ${ }^{19} \mathrm{E}$ por isso que, para o autor, "A epoché não é certamente em si já um método. Ela é no máximo um pedaço de método" (Husserl, 1984/ 2008c, p. 189, grifo do autor, tradução nossa).

Em suma, o conceito de Redução Fenomenológica nasce completamente relacionado à noção de Teoria do Conhecimento e o necessário estatuto de evidência desta (que aqui também significa o "indubitável”). Só precisamos excluir a esfera da transcendência mundana porque ela não apresenta tal caráter.

\section{2. $1910-1913$}

Nesta seção, abordaremos a forma com a qual o conceito de Redução Fenomenológica foi desenvolvido nos anos 1910 até 1913. Acreditamos que houve mudanças significativas em relação ao período anteriormente abordado. Por isso, cremos poder ser considerado aqui uma nova "fase" do pensamento husserliano sobre o nosso conceito-alvo. Também, na medida do possível, tentaremos traçar paralelos entre as concepções da seção anterior, marcando as modulações conceptuais que possam ter ocorrido. Para tanto, utilizaremos, como "dados exemplares", as obras "Ideias para uma Fenomenologia Pura e uma Filosofia Fenomenológica” (Ideen zu einer reinen Phänomenologie und phänomenologischen Philosophie) e "Problemas Fundamentais da Fenomenologia” (Grundprobleme der Phänomenologie).

\section{A noção de dependência/independência para a de- limitação do alcance da redução fenomenológica}

Como principal aquisição ${ }^{20}$ para o conceito de Redução Fenomenológica presente nesta fase, temos o papel da dependência/independência ${ }^{21}$ que o fatual das ciências naturais ocuparia em relação à ideia de consciência. A primeira informação de que precisamos aqui saber é que apreensão fenomenológica é uma mudança radical na lógica do pensamento

\footnotetext{
19 Nesta época, por exemplo, era comum o uso "Epoché em relação a toda transcendência", "nossa Epoché" etc. Mais tarde, Husserl utiliza termos como "Epoché Transcendental", por exemplo, para fazer tal restrição.

20 Não queremos dizer que esta noção não tenha sido aqui e ali aludida anteriormente por Husserl em suas obras passadas. Porém só agora a noção de dependência/independência dos elementos que serão aqui trabalhados teve uma madura sistematização e articulação com o conceito de Redução Fenomenológica.

21 É neste ínterim que Husserl retoma, de maneira notável, o que ele postulou nas Investigações Lógicas como "teoria dos todos e das partes" (Husserl, 1901/ 2015).
}

natural. Este, segundo Husserl, defende exatamente o contrário: o ser fatual é um dado absoluto ao qual se subordina o ser da consciência, a res cogitans se subordina à res extensa. "Imputa-se, assim, ao físico uma realidade mítica absoluta” (Husserl, 1913/2006, p. 124). Temos aqui o "mundo ${ }^{22}$ ", o fato como um grande todo, em que nada lhe escapa, não sendo subordinado (untergeordnet) a mais nada.

Sob um ponto de vista do ser próprio do mundo e da consciência, entretanto, a tese natural não se sustenta. Como o mundo não é aparentado por essência da consciência absoluta, ele não pode fazer parte desse todo. $\mathrm{Na}$ verdade, ele constitui outro todo, em que nada necessita daquele. É daí que ele tira seu caráter de independência em relação à consciência. Segundo o autor, não pode haver uma subordinação da consciência em relação ao factual, seguindo a tese natural. Res cogitans é algo que "pode se separar" (Husserl, 1973/1991, p. 135, tradução nossa) da res extensa. Por exemplo, "na essência de uma dor ou de um prazer, não há dado absolutamente nenhuma relação [essencial] a uma coisa (...). Mas, se for deste modo, nós podemos cortar a relação empírica entre cogitatio e res." (Husserl, 1973/1991, p. 136, tradução nossa). Neste sentido, para Husserl (1913/2006), “um verdadeiro abismo de sentido se abre entre consciência e realidade" (p. 116). O que importa, em suma, em coisas desta ordem, é que há uma vinculação necessária, segundo a atitude natural e, portanto, com base na experiência (Erfahrung), entre coisas que podem, sem contrassenso, ser separadas, ou seja, não têm entre si uma relação essencial.

Ora, temos aqui dois estados de coisas diferentes, sendo que em nenhum deles ainda foi aplicada a redução fenomenológica. Temos, por um lado, a apreensão da atitude natural, em que temos um só todo absoluto (mundo) e a consciência (que aqui teria o caráter de "res") seria um elemento subordinado do factual-real. Por outro lado, temos uma consideração "pré-fenomenológica”, em que se toma, por essência, esses dois tipos de dados como desaparentados, todos totalmente independentes entre si.

Não obstante, Husserl apresenta o ser real existente como relativo e contingente. Isto quer dizer que ele é de certo modo, mas poderia ser de outro modo completamente diferente. "Quer dizer: sempre pode ser que o transcurso posterior da experiência obrigue a abrir mão daquilo que já está posto com legitimidade empírica” (Husserl, 1913/2006, p. 109).

Já o ser absoluto é de outra ordem. "Conflito, ilusão, ser outro não tem espaço na esfera absoluta” (Husserl, 1913/2006, p. 109). Este ser é completamente necessário e absoluto. Ele não "poderia ser de outro modo". Em suma,

22 Definido aqui como um "conjunto completo dos objetos da experiência possível e do conhecimento possível da experiência, dos objetos possível de ser conhecidos com base em experiências atuais do pensamento teórico-concreto" (Husserl, 1913/2006, p.34). 
(...) tese do mundo, que é uma tese 'contingente', contrapõe-se, portanto, a tese de meu eu puro e da vida do eu, que é uma tese 'necessária', pura e simplesmente indubitável. Toda coisa dada em carne e osso também não pode ser, mas não um vivido dado em carne e osso (Husserl, 1913/2006, p. 109).

A consciência pura adquire aqui o caráter de um todo absoluto e fechado em si. Em outras palavras, ela

(...) tem de valer como uma concatenação de ser fechada por si, como uma concatenação do ser absoluta, no qual nada pode penetrar e do qual nada pode escapulir; que não tem nenhum lado de fora espaço-temporal e não pode estar em nenhum nexo espaço-temporal, que não pode sofrer causalidade de coisa alguma, nem exercer causalidade sobre coisa nenhuma - supondo-se que causalidade tenha o sentido normal de causalidade natural, enquanto relação de dependência entre realidades (Husserl, 1973/1991, p. 151).

Não é difícil ver que apenas a consciência pura é capaz de fornecer o conhecimento intuitivo que a fenomenologia requer. Apenas neste âmbito absoluto é imperativo “voltar às coisas mesmas". É preciso, portanto, para franquear acesso a esse âmbito, excluir $^{23}$ tudo aquilo que dele não faz parte, a saber, $a$ tese geral do mundo.

É, então, por causa daquela citada independência que Husserl defende a "aniquilação do mundo" pela via da Redução Fenomenológica. Portanto, mesmo com esta, o ser dos vividos "permaneceria intocado em sua própria existência” (Husserl, 1913/2006, p. 115). Aqui, por conseguinte, temos um interessante detalhe adquirido: Husserl justifica a operação de exclusão porque

\footnotetext{
23 Sobre o "excluir", "pôr entre parênteses", há algumas concepções concernentes nesta obra. Husserl chama os atos de crença por, também, "atos téticos". Estes teriam algo como certo, seriam teses de posição do ser. Uma aquisição teoria importante com esta nova nomenclatura diz respeito a noção de crença (ou doxa) originária. Assim, todas as modalidades de crença teriam, necessariamente, de se remeter intencionalmente, a um conteúdo de crença originário, sendo aquelas, modificações destes. Das modificações apresentadas por Husserl, a mais importante para nossa pesquisa é a noção de "modificação de neutralização". Esta modificação, que notadamente é aquela praticada pela Epoché, tem por caráter essencial "esgotar" completamente toda modalidade doxa justamente de seu caráter de crença. Ela não nega, nem assere, mas sim neutraliza. Assim, "o caráter de posição fica sem efeito. A crença já não é então seriamente uma crença, a conjectura, uma negação, etc. 'neutralizadas', cujo correlatos repetem aqueles dos vividos não-modificados, mas de uma maneira radicalmente modificada: o pura e simplesmente existente, o possivelmente existente, o verossimilhantemente existente, o não-existente e todos os demais negados e afirmados estão ali para consciência, não, porém, no modo do efetivo, mas como algo 'meramente pensado', como 'mero pensamento". (Husserl, 1913/2006, p. 243). Contudo, apesar das pequenas modificações, é Husserl (1913/2006) que reconhece que esta noção está presente em sua obra desde cedo, já nas Investigações. "Quanto à doutrina de modificação de neutralização, que se tratou até aqui, as investigações lógicas já chegaram, no principal, até a apreensão correta, especialmente no que se refere à relação com a mera imaginação" (p. 248).
}

(...) trata-se de mostrar que há uma consciência pura, e que a consciência pura, mesmo modificada, fica como resto enquanto meu ego cogito, mesmo se o mundo não existe. Eu vejo em seguida que eu não posso certamente riscar meu ego, ainda que o domínio das possibilidades ontológicas que este da fenomenologia eidética pura é independente da existência de um mundo objetivo (Husserl, 1973/1991, p. 110).

Quando, todavia, estamos na atitude fenomenológica propriamente dita, a consciência absoluta é o fundamento de qualquer postulação em relação ao mundo. Já que "a formação de um todo só é possível para aquilo que é aparentado por essência” (Husserl,

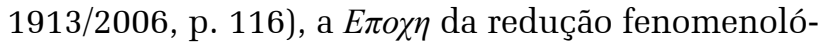
gica trata de fazer este "aparentamento". O mundo, portanto, torna-se dependente, "subordinado" da esfera fenomenológica absoluta, um "mero ser intencional”. A redução fenomenológica seria o que definiria, portanto, tal "subordinação". O que "sobra", o "resíduo fenomenológico" é, portanto, um todo em que não há mais nada que se encontre alienado a ele mesmo. Não há mais como pôr o mundo como se punha na atitude natural. O dado real se encontra agora dentro desse todo. Em outras palavras, a redução operaria uma "exclusão inclusiva". O filósofo ilustra muito bem este estado de coisas, afirmando que

(...) por outro lado, todo o mundo espaço-temporal, no qual o homem e eu humano se incluem como realidades individuais subordinadas, é segundo seu sentido, mero ser intencional, portanto, tal que tem o sentido meramente secundário, relativo de ser para consciência. Ele é um ser de que a consciência põe existência em suas experiências, que por princípio só intuível e determinável como o idêntico de multiplicidades de aparições motivadas de modo coerente mas, além disso, um nada (Husserl, 1913/2006 p. 116, grifo nosso).

\section{Redução e disciplinas formais}

Uma mudança de posicionamento de Husserl diz respeito a relação de inclusão/exclusão de certos conhecimentos formais por parte da redução. Na fase abordada na seção anterior, Husserl, claramente, defende exclusão de disciplinas formais pela redução fenomenológica. Em primeiro lugar, o autor advoga uma exclusão da lógica.

Mas de que serve referir contradições, se a própria lógica está em questão e se tomou problemática? Efetivamente, a significação real e a legalidade lógica, que está fora de toda a questão para o pensamento natural, torna-se agora problemática e, inclusiva, duvidosa (Husserl, 1954/ 2008b, p. 41). 
A matemática, desse modo, também não seria tomada à maneira das ciências naturais, ou seja, de modo “fora de questão". Para Husserl, (1954/2008b), "o conhecimento intuitivo da cogitatio é (...) mas também, vendo de perto, o das ciências matemáticas, é transcendente” (p. 21) e, ainda, “toda inquirição é, pois, apriorística; naturalmente, não é apriorística no sentido das deduções matemáticas" (p. 65). O que a diferencia das ciências apriorísticas objetivantes é o seu método e o seu objetivo. (...) Não teoria nem matematiza” (p. 85). Não devemos tomar o conhecimento matemático, portanto, por não apresentar caráter apriorístico.

Husserl, entretanto, muda visivelmente de posicionamento nesta fase atual. A matemática não

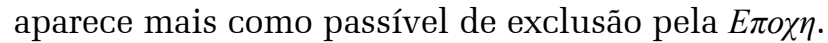
"Pôr o mundo fora de circuito não significa efetivamente colocar fora dele, por exemplo, a teoria dos números e a aritmética a ele referente" (Husserl, 1913/2006, p. 83). Isto ocorre puramente por questões sobre o próprio ser da consciência. Agora, o filósofo percebe o vivido puro como, por essência, inerente ao conhecimento de tais disciplinas. Por isso,

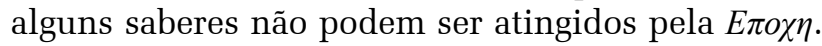
Segundo a pena do autor,

(...) todo vivido puro também está subordinado ao sentido lógico mais amplo de objeto. Não podemos pois - assim parece - colocar a lógica e a ontologia fora de circuito. E tão pouco, por razões manifestadamente iguais, a noética em geral, que exprime conhecimentos de essência sobre a racionalidade ou irracionalidade do pensamento judicativo em geral, cujo conteúdo de significação é determinado apenas em generalidade final (Husserl, 1913/2006, p. 135, grifo nosso).

Para se manter no escopo daquele horizonte aberto da consciência pura, Husserl defende que a redução fenomenológica não pode colocar fora de circuito nada que esteja subordinado ao vivido de consciência. Percebe-se que o autor continua, como nos anos anteriores, a "se guiar", de início, pelo dado das cogitationes, do vivido de consciência ${ }^{24}$. Portanto, o ser "reelle" (incluso) continua sendoa "pedra-de-toque" da redução fenomenológica. Este dado cartesiano é aquilo a partir do qual toda a fenomenologia vai tirar seu caráter de exceção ao natural.

\section{Uma "análise eidética" antes da Redução Fenome- nológica}

Uma importante nuance teórica inaugurada nesse período diz respeito a uma espécie de "análise eidética” necessária que deveria ocorrer antes de toda redução à consciência pura. Segundo o au-

24 "Consciência pura", como Husserl costuma utilizar nesta época. tor, a consciência necessita ter, antes de tudo, como vimos, um "ser próprio", que justifique toda a sua necessidade absoluta e, portanto, sua não exclusão. Provemos nosso posicionamento, agora, com elucidativas palavras do autor:

(...) antes de tudo, ainda sem excluir fenomenologicamente os juízos de circuito, submetemo-los a uma análise eidética sistemática, embora ainda não de todo exaustiva. Aquilo de que indispensavelmente precisamos é certa evidência geral sobre a essência da consciência em geral, e muito particularmente também daquela consciência na qual, por sua essência, se é consciente da efetividade 'natural'. Seguimos nestes estudos até onde for necessário para levar a cabo a evidência de que a consciência tem em si um ser próprio, o qual não é atingido em sua essência própria absoluta - pela exclusão fenomenológica. A consciência remanesce, assim, como 'resíduo fenomenológico', como uma espécie própria por princípio de região do ser, que pode, com efeito, tornar-se o campo de uma nova ciência (Husserl, 1913/2006, p. 84, grifo nosso).

Tal tomada de posição difere consideravelmente da apresentada na fase passada. Naquela época, Husserl tomou as cogitationes como meramente "dados singulares" 25 . Ele defendia que poderíamos chegar a dados eidéticos apenas em um momento "ulterior".

Defende-se que tal estado de coisas ocorreu devido à própria apreensão da relação entre fato/ essência ocorrida nesta nova fase. No período anterior, Husserl claramente tinha em mente a necessidade da não-limitação à dados singulares. Fenomenologia, como teoria do conhecimento, é ciência da "essência", das "fontes do conhecimento". Husserl percebe que um conhecimento de tal ordem nunca poderia ser de singularidades. Por isso, afirma que há "certa estreiteza" no "primeiro grau da consideração fenomenológica” (cogitatio), que "não parece satisfazer capazmente as nossas intenções". (Husserl, 1954/2008b, p. 25, grifo nosso). Portanto, o que há aqui é uma espécie de "necessidade teórica" da ampliação ao eidético. A “intenção” de ciência husserliana estaria afetada, se houvesse tal limitação. Assim, teríamos condições, seguindo a lógica das obras da época, de apreender um dado singular como pura singularidade, sem referência necessária à generalidades. Contudo, tal intento seria, para o autor, infértil.

O que muda, de maneira interessante, aqui é essa própria relação de dependência do eidético para com o factual ${ }^{26}$. Husserl argumenta que quan-

25 Ainda que aí se utilizasse de elementos já eidéticos (como, por exemplo, a justificativa da sua necessária intencionalidade, o que já aponta, de certa maneira, uma inclinação para o posicionamento mais maduro).

26 Essa é, inclusive, uma nova crítica que Husserl faz às Ciências da Natureza. O problema presente no conhecimento fatual (ciências de fato) diz respeito ao seu caráter dependente do eidético (ciências de essências), 
do afirmamos que, "por sua essência própria”, todo fato é contingente já exprime o fato de que "faz parte do sentido de todo contingente ter justamente uma essência e, por conseguinte, um eidos a ser apreendido em sua pureza, e ele se encontra sob verdades de essência de diferentes níveis de generalidades" (Husserl, 1913/2006, p. 35, grifo nosso). Assim, é, para o Husserl desta fase, impensável, diferente do da fase anterior, algo como um dado em sua "singularidade" pura.

\section{Considerações finais: uma tendência à constância na Redução}

Como podemos constatar, na última sessão, o conceito "Redução Fenomenológica" manteve em grande parte a essência do que Husserl já postulara no momento anterior. Como vimos, a mudança mais acentuada foi em relação à sistematização da abrangência da $E \pi o \chi \eta$ pela via "dependência/independência". A ideia de que a teoria do conhecimento deveria começar por uma "clara et distincta perceptio" (o cogito, no caso) e, por isso, a redução deveria excluir aquilo que não tivesse tal caráter (a transcendência) perde, em certa medida, sua força. Na verdade, o que é mais dominante aqui é a ilustração de uma consciência pura como um todo absoluto e necessário, independente de qualquer dado empírico e, por isso, possibilitada a sua exclusão.

Por outro lado, aconteceram nuances no conceito (que era considerado na fase anterior como franqueador para singularidades) de ordem eidética. Por um lado, é, digamos assim, "salvo" da exclusão fenomenológica disciplinas formais, pois o cogito é, eideticamente, subordinado a elas.

Ainda sobre esse aspecto, Husserl considera que a consciência pura não pode mais ser considerada como um dado singular. Para tanto, ela deve ser, antes de qualquer coisa, analisado eideticamente, sendo assim não mais um dado singular. Com isso, é possível concluir que a diferença entre singular/geral, de certo modo, perde sua força. A fronteira entre esses dois tipos de dados aqui fica mais fluida.

Diante disso, até onde nossa pesquisa pôde abarcar, a Redução Fenomenológica apareceu, de um ponto de vista histórico, como um edifício firme e consistente, com a uniformidade esperada para fundamentar um método rigoroso. Recomenda-se, para futuras pesquisas, ainda, a extensão de tal estudo a fim que cubra o resto do período producente de Edmund Husserl. enquanto este é independente do fatual. Tal necessidade torna necessária a subordinação da esfera fatual para com uma esfera eidética, como o eu puro. Assim, para Husserl, toda ciência de fato tem fundamentos teóricos essenciais em ontologias eidéticas. Negar o conhecimento eidético, como fazem as ciências fatuais, torna-se, assim, um contrassenso.

\section{Referências}

Bernet, R., Kern, I., \& Marbach, E. (1999). An introduction to husserlian phenomenology. Illinois: Northwestern University Press.

Brainard, M. (2003). Reducing the reduction: Husserl's many ways to one reduction. Alter: Revue de Phénomenologie, 11(1), 79-90.

Fragata, J. (1963). Problemas da fenomenologia de Husserl. Braga: Livraria Cruz.

Husserl, E. (1980). On the phenomenology of the consciousness of internal time (1893-1917). Londres: Kluer Academic Publishers. (Original publicado em 1966).

Husserl, E. (1991). Problèmes fondamentaux de la phénoménologie. Paris: Presses Universitaires de France. (Original publicado em 1973).

Husserl, E. (1994). Lições para uma fenomenologia: da consciência interna do tempo. Lisboa: Imprensa Nacional. (Original publicado em 1966).

Husserl, E. (2001). Psychologie Phénomenologique (1925-1928). Paris: Vrin. (Original publicado em 1962).

Husserl, E. (2006). Idéias para uma fenomenologia pura e para uma filosofia fenomenológica: introdução geral à fenomenologia pura. São Paulo: Ideias \& Letras. (Original publicado em 1913).

Husserl, E. (2008a). Lições sobre a teoria da significação. Lisboa: Centro de Filosofia da Universidade De Lisboa. (Original publicado em 1987).

Husserl, E. (2008b). A Idéia da Fenomenologia. Lisboa: Ed. 70. (Original publicado em 1954).

Husserl, E. (2008c). Introduction to logic and theory of knowledge lectures 1906-07. New York: Springer. (Original publicado em 1984).

Husserl, E. (2015). Investigações Lógicas - investigações para a fenomenologia e a teoria do conhecimento. Aparecida: Forense Universitária. (Original publicado em 1901).

Kern, I. (1962). Die drei Wege zur Transzendentalphaenomenologischen Reduktion Edmund Husserls. Tijdschrift Voor Filosofie, 24(2), 303349.

Lavigne, J-F. (2003). La réduction phénomenologique dans les Recherches Logique selon leur première edition, 1901. Alter: Revue de Phénomenologie, 11(1), 23-49.

Lohmar, D. (2003). L'Idée de la Réduction. Les reduction de Husserl - et leur sens méthodique commun. Alter: Revue de Phénomenologie, 11(1), 91-110. 
Merleau-Ponty, M. (1960). Le Philosophe et son ombre. Em Merleau-Ponty, M. Signes, Paris, Edições Gallimard.

Moran, D., \& Cohen, J. (2013). The Husserl dictionary. Londres: Bloomsbury.

Tourinho, C. (2012). O transcendente e suas variações na fenomenologia transcendental de Edmund Husserl. Prometeus. Filosofia em Revista, $5,27-41$.

Ícaro Miguel Ibiapina Machado (Orcid: 0000-00031759-2930) é Psicólogo formado pela Universidade Federal do Ceará, mestre pelo Programa de PósGraduação em Filosofia, na Universidade Federal do Piauí (UFPI), e, atualmente, doutorando pelo Programa de Pós-Graduação em Filosofia, na Universidade Federal de Santa Catarina (UFSC). Endereço: Avenida Romualdo de Barros, 997. CEP: 88040-600. Florianópolis-SC. Email: icaro_ machado@live.com

Recebido em 27.06.2018

Primeira Decisão Editorial em 21.11.2018

Aceito em 11.12.2018 